\title{
The Impact of Spiritual Wellbeing and Coping Strategies on Patients with Generalized Anxiety Disorder
}

\author{
Faiza Amjad
}

Centre for Clinical Psychology, University of the Punjab, Lahore, Pakistan

\section{Dr. Iram Zehra Bokharey}

Senior Clinical Psychologist, Punjab Institute of Mental Health, Lahore, Pakistan

\begin{abstract}
The present study aimed to investigate the spiritual wellbeing and coping strategies of participants with generalized anxiety disorder (GAD). This study included 40 participants with GAD, all meeting the diagnostic criteria of the DSM IV-TR. The Spiritual Wellness Inventory and the Coping Strategies Questionnaire were used as measuring tools. The data were analyzed by descriptive statistics, linear and stepwise regression, and Sobel z-test of mediation analysis. The stepwise regression analysis showed that out of 13 dimensions of spiritual wellness, only three dimensions (i.e., concept of hereafter, mystery, and meaning) significantly predicted GAD symptoms in negative direction. The mediational analysis showed that active practical and religious coping strategies did not mediate between the relationship of spiritual wellness and symptoms of GAD.
\end{abstract}

Keyword: spiritual wellbeing, coping strategies, Generalized Anxiety Disorder, mediational Analysis

Religion and spirituality are traditional means of coping, as they promote an internal locus of control in stressful situations (Barbarin, 1993; Hefti, 2011). The religious and spiritual activities help to reframe stressful events in a way that motivates the individual intrinsically to deal with life stressors. The origin of word spirituality is from the Latin word 'spiritus', meaning "breath" or "life" 
(Elkins, 1999). The term spirituality can be defined as "a subjective belief system that incorporates self -awareness and reference to a transcendence dimension, provides meaning and purpose in life, and feelings of connectedness with God or the larger reality" (Bensley, 1991, p. 288). Whereas, Koenig, George, and Titus (2004) conceptualized religion as "an organized system of beliefs, practices, rituals, and symbols designed to facilitate closeness to the sacred or transcendent". However, religious activities may be the source of nurturing spirituality, and healthy religious activities provide a medium for the expression of spirituality (Elkins et al., 1988). Though religion is culturally flavored, individuals use their religion for the expression and development of their spiritual capacities (Campbell, 1969; Ingersoll, 1994).

In the recent past, researchers and mental health professionals have shown interest in investigating the impact of spirituality on mental health. Smith (1994) suggested that the roles of spirituality and health have always been interrelated, as the fulfillment of biological, psychosocial, and spiritual needs are associated with human illness and suffering. Spirituality is a determinant of better mental health because it can serve as a source of hope and strength in times of crises (Koenig, McCullough, \& Larson, 2001). It also promotes reframing problems, and perseverance in the face of psychosocial stressors (Hefti, 2011). Moreover, Frankl (1964) was of the view that spirituality is associated with meaning in life, and a lack of life meaning is associated with various psychopathologies. There is a need for psychologists to understand how the spirituality of an individual impacts different aspects of life (i.e., interpersonal, cognitive, behavioral, and affective), to understand spirituality's role in mental as well as physical health (Hill et al., 2000). Likewise, Mohamed (1998) proposed that equilibrium between the physical/worldly needs and spiritual needs is required, as both seem to be integral parts of human nature.

Spirituality can also motivate a person toward the use of effective coping strategies. Lazarus and Folkman (1984) defined coping as cognitive and behavioral efforts aimed to manage external or internal demands that exceed the resources of the person. They proposed two types of coping strategies, emotion-focused coping strategies aimed at alleviating negative emotions, and problem-focused coping strategies that include efforts to deal with stressful situations directly. There have been a range of suggestions for how spirituality affects coping strategies. For instance, Barbarin (1993) suggested that, in stressful situations, spirituality enhances resilience and optimism. Similarly, Hefti (2011) was of the view that spirituality increases personal empowerment in the face of stressors with the sense of being secured by God. It was also postulated that spirituality increases reliance on problem-solving strategies (Pargament et al., 1992), a sanguine choice, compared to surrendering to the stressors (Carver, Scheier, \& Weintraub, 1989).

As spirituality is a subjective experience, it is difficult to measure, though 
there are indicators of spirituality that enable this construct to be measured directly (Moberg, 2002). In order to quantitatively investigate and describe the construct of spirituality, it is necessary to discuss it in the framework of spiritual wellbeing and wellness (Ellison, 1982; Ingersoll, 1994), which is the reflection of one's spiritual health and spiritual maturity (Ellison, 1982). Gomez and Fisher (2003) defined spiritual wellbeing as

A state of being, reflecting positive feelings, behaviors, and cognitions of relationships with oneself, others, the transcendent and nature, that in turn provide the individual with a sense of identity, wholeness, satisfaction, joy, contentment, beauty, love, respect, positive attitudes, inner peace and harmony, and purpose and direction in life. (p. 1976)

Like indicators of the physical health, spiritual wellness has different dimensions of expression (Ingersoll \& Bauer, 2004). Fisher (2011) proposed that spiritual wellbeing is manifested through four domains of life, the personal, communal, environmental, and transcendental domains. He further explained that enhancement of spiritual wellbeing depends on developing healthy relationships in each domain. In contrast, Ingersoll (1998) proposed 10 dimensions of spiritual wellbeing: conception of divinity, meaning, connectedness, present-centeredness, mystery, rituals, hope, forgiveness, knowledge/learning, sense of freedom. He describes the conception of divinity as reflecting a personal image or experience of the absolute, and the dimension of meaning expressed as a sense that life is worth living and purposeful, as well as a sense of being at peace. Connectedness refers to the relationship with other people, God, and with the environment. The dimension of mystery measures the person's comfort level and ways of dealing with the ambiguities and uncertainties of life. Spiritual freedom is associated with a sense of freedom from internal and external compulsions, and willingness to make a commitment. The rituals dimension includes healthy spiritual rituals and practices, while dimension of forgiveness shows person's inclination of giving and receiving forgiveness. Ingersoll suggested that hope dimension reflects the person's belief that his sufferings are not in vain or going to last forever and it reflects the sense of being safe in life. The dimension of knowledge/learning shows the increased interest in getting knowledge of self and other things in the environment, while present-centeredness depicts one's ability to be aware of the present moment.

The present study aimed to explore the specific dimensions of spiritual wellbeing, proposed by Ingersoll (1998), that significantly predict the intensity of generalized anxiety disorder, and the types of coping strategies that mediate the relationship between spiritual wellbeing and generalized anxiety disorder. This research would help to reveal the importance of conceptualizing the mental disorders by considering the spiritual aspect along with the 
prevalent bio-psychosocial model. The literature review suggested that very few studies had specifically investigated the dimensions of spiritual wellbeing in relation to psychopathologies. Graybill and Esquivel (2012) explored the predictive power of dimensions of spiritual wellness on depression among the mothers of children with autism spectrum disorders; they found that, out of four dimensions of spiritual wellness, meaning/purpose in life and inner resources significantly and negatively predicted maternal depression. However, positive interconnectedness and transcendence did not significantly predict maternal depression. Similarly, a meta-analysis showed that meaning in life, transcendent perspective, intrinsic value system, sense of belonging to a spiritual community of shared values, and support negatively predicted depression (Westgate, 2011). Moreover, Maselko, Gilman, and Buka (2009) found that, of two dimensions of spiritual wellbeing (religious wellbeing and existential wellbeing), there was negative association between existential wellbeing and severity of depression, and nonsignificant positive association between religious wellbeing and depression.

Few studies have investigated the mediation effect of spirituality-related coping strategies on mental disorders, but the findings of these studies have been contradictory. Perez and colleagues (2009) found a negative association between spiritual striving and levels of depressive symptoms, and a positive relationship between spiritual striving and acceptance coping. That study also reported that acceptance coping mediated the relationship between spiritual striving and depressive symptoms. However, Watlington and Murphy (2006) found that religious coping did not mediate the relationship between spirituality, depression, and posttraumatic stress symptoms. The present study focused on investigating spiritual wellbeing and coping strategies of patients with Generalized Anxiety Disorder. In the light of the literature review, the following hypotheses were formulated for present study:

1. The different dimensions of spiritual wellbeing will negatively predict the intensity of symptoms of Generalized Anxiety Disorder.

2. Coping strategies will mediate the relationship between spiritual wellbeing and symptoms of Generalized Anxiety Disorder.

The first hypothesis aimed to explore the specific dimensions that individually and significantly predict the intensity of symptoms of Generalized Anxiety Disorder. The Ingersoll spiritual wellness inventory and assumptions (1998) were used, and, accordingly, as each of the dimensions of spiritual wellbeing is complementary with others (i.e., a high score in the meaning dimension will indicate high score in dimensions of hope, connectedness, presentcenteredness etc.), it was hypothesized that wellbeing in each dimension of spirituality would result in reduction of symptoms of GAD. The second goal 
was to investigate whether spiritual wellbeing has a direct impact on GAD, or whether it would affect GAD via coping strategies.

\section{Method}

\section{Participants}

This study employed cross-sectional survey design. The sample was comprised of 40 participants with Generalized Anxiety Disorder (GAD). G*Power 3.1 software was used for power analysis with multiple regression model (Faul, Erdfelder, Buchner, \& Lang, 2009). The power of the study with the sample size of 40 and two predictor variables came out to be .77, by assuming the medium effect size of .15. All the participants were selected by the purposive sampling method. The participants with GAD fulfilling the following criteria were included in this study:

- The participants fulfill the diagnostic criteria of GAD according to the DSM-IV TR.

- The age range of the participants was 18 years and above.

- The minimum education of five years of participants was required.

- In case of comorbidity with GAD, it was required that GAD should be their primary diagnosis.

- The participants with GAD found in comorbidity with any psychotic disorder, substance-related disorders and with extreme general medical conditions (i.e., cancer, hepatitis, cardiovascular disease, severe head injury, and HIV/AIDS) were excluded.

All the participants were Muslims in Pakistan. Out of 40 participants with GAD, 22 were men and 18 were women. The distribution of ages varied, with 18 participants between 18 and 28 years old, 8 participants aged 29-38 years, and 10 were $39-48$ years old. The age ranges with the fewest participants were in the categories of 49-58 and 59-64, with 3 and 1, respectively. With respect to education levels, nine participants had between 5 and 7 years of schooling, 11 participants had 8-10 years of education, five participants had been educated for 11-13 years, and 14 had had 14 to 16 years of school. One participant had 17-18 years of education.

Of the 40 participants, the length of illness thus far for 12 participants was one year; two years for 4 participants; three years for 5 participants; four years for 4 participants; five years for three participants; six years for two participants; and one participant had had GAD for each of eight, nine, and ten years, respectively. For those with a diagnosis less than a year old, three participants 
had six months of illness, one participant had seven months, two participants had eight months, and one participant had ten months.

\section{Measures}

\section{The Spiritual Wellness Inventory}

This inventory (Ingersoll, 1998) was adapted into Urdu by Gohar (2005). It includes 65 items. Each item was rated on a four-point Likert scale, ranging from 1 (strongly disagree) to 4 (strongly agree). This inventory consists of 13 dimensions of spiritual wellness, described previously. The convergent validity of the Urdu version of the spiritual wellness inventory was $r=.97$, while the discriminant validity was $r=-.63$ (Gohar, 2005). The reliability of the Urdu version of the inventory was reported as $r=.74$ (Batool, 2009). The Cronbach's alpha reliability of this inventory in the present research was calculated as $r=.75$.

\section{The Coping Strategies Questionnaire}

This questionnaire (Kauser \& Munir, 2004) is comprised of 62 items. Each item was rated on a five-point Likert scale, ranging from 1 (not applied at all) to 5 (used very much). The alpha reliability of the questionnaire was .89 , while the internal consistencies of CSQ subscales were .72 for active-practical coping strategies, .58 for active-distractive coping strategies, .55 for avoidance-focused coping strategies, and .73 for religious-focused coping strategies. In the present research, the Cronbach's alpha reliability of the questionnaire was .85.

\section{Procedure}

The data were collected from the outpatient departments of government teaching hospitals in Lahore (i.e., General Hospital, Mayo Hospital, Sir Ganga Raam Hospital, Services Hospital, Punjab Institute of Mental Health, Jinnah Hospital, and the Centre for Clinical Psychology). The data from participants with GAD were collected after taking permission from the head of psychiatry. The psychiatrists and clinical psychologists of the hospitals were asked to refer patients diagnosed with GAD. The clinical diagnoses of the referred patients were reinforced by conducting interviews, according to the diagnostic criteria of DSM-IV-TR, and recording participant ratings on each criterion. The Cronbach's alpha reliability of these ratings was calculated as $r=.76$. To rule out the possibility of psychotic features, mental state examination (Gelder, Gath, Mayou, \& Cowen, 1987) was done. The questionnaires were then administered by the researcher. Ethical considerations of conducting research were a top pri- 
ority, including written informed consent from the research participants, strict confidentiality, and participants were given the right to withdraw at any stage of research.

\section{Results}

The data of 40 participants with GAD was entered into Statistical Package for Social Sciences (SPSS) 17. In order to obtain results the descriptive statistics, linear and stepwise-regression analysis were performed. The mean, standard deviation, frequencies and percentages of demographic variables were obtained by employing descriptive statistics. The dimensions of spiritual wellbeing as predictors of intensity of GAD were analyzed by using stepwise-regression analysis. To analyze the mediating effect of coping strategies between the relationship of spiritual wellbeing and severity of GAD symptoms, linear and hierarchical stepwise-regression analysis was used. Sobel z-test was used to confirm the mediation analysis.

Table 1 shows that the mean age of 40 participants with generalized anxiety disorder was 33.07 , the mean of years of education was 10 years, 8 months, and the mean of participant monthly incomes was 28250 rupees. Of the participants, $22(55 \%)$ were men and $18(45 \%)$ were women. Half of the participants (20) were married, and two (5\%) were divorced. The table also showed the frequencies and percentages of participants belonged to different occupations. Two (5\%) participants were jobless, six (15\%) were students, and 11 (27.5\%) were housewives.

Table 2 shows that, out of 13 dimensions of spiritual wellness, only three dimensions significantly predicted Generalized Anxiety Disorder. The concept of hereafter $(\beta=-0.53, p=.00$, one tailed $)$, mystery $(\beta=-0.46, p=.00$, one tailed) and meaning ( $\beta=-0.26, p=.04$, one tailed) significantly negatively predicted intensity of GAD symptoms. The stepwise-regression analysis gave three values of $R^{2}$. In step 1 , it showed that $28 \%$ of variation in dependent variable (severity of GAD symptoms) was because of the independent variable (concept of hereafter), whereas in step 2, the value of $R^{2}=.49$ showed that concept of hereafter as well as mystery accounted for $49 \%$ of variability in GAD symptoms together. Finally, in step 3, the value of $R^{2}=.54$ depicted that total $54 \%$ variation in GAD symptoms was because of these three independent dimensions of spiritual wellbeing together (i.e., concept of hereafter, mystery, and meaning). Furthermore, it was the value of $R^{2}$ change that showed the individual contribution of each dimension to variability of GAD symptoms. The concept of hereafter $\left(R^{2}\right.$ change $\left.=.28\right)$ accounted for $28 \%$ of variability in GAD symptoms, mystery $\left(R^{2}\right.$ change $\left.=.21\right)$ accounted for $21 \%$, and meaning $\left(R^{2}\right.$ change $\left.=.05\right)$ 
TABLE 1. Mean and Standard Deviation of age, years of education, monthly income, gender, occupations, and marital status of participants with Generalized Anxiety Disorder $(n=40)$

\begin{tabular}{lcc}
\hline Variables & $M$ & $S D$ \\
\hline Age & 33.07 & 12.04 \\
Education & 10.80 & 3.81 \\
Monthly income & 28250 Rupees & 18509.53 Rupees \\
& $(275.21$ \$US $)$ & $(180.32 \$$ US $)$ \\
Gender & $F$ & $\%$ \\
Men & & \\
Women & 22 & 55.0 \\
Marital Status & 18 & 45.0 \\
Unmarried & & \\
Married & 18 & 45.0 \\
Divorced & 20 & 50.0 \\
Occupations & 2 & 5.0 \\
$\quad$ None & & \\
Student & 2 & 5.0 \\
Employee & 6 & 15.0 \\
Housewife & 5 & 12.5 \\
Teacher & 11 & 27.5 \\
Tailor & 1 & 2.5 \\
Lawyer & 1 & 5.0 \\
Electrician & 2 & 2.5 \\
Painter & 1 & 2.5 \\
Mason & 1 & 7.5 \\
Salesmen & 3 & 5.0 \\
Shopkeeper & 2 & 5.0 \\
Banker & 2 & 2.5 \\
Doctor & 1 & 5.0 \\
\hline Note:M Man & 2 &
\end{tabular}

Note: $M=$ Mean, $S D=$ Standard Deviation, $f=$ Frequencies, $\%=$ Percentages.

accounted for 5\% variability in GAD symptoms. The other dimensions were excluded from the model of stepwise-regression analysis as these dimensions nonsignificantly predicted GAD in negative direction.

\section{Test of Mediation}

In order to test the hypothesis that coping strategies will mediate the relationship between spiritual wellbeing and the intensity of symptoms of generalized anxiety disorder, the statistical model of mediation (Baron \& Kenny, 1986) was used. According to Baron and Kenny (1986), the following conditions must be satisfied in order to find mediation effect: (a) the predictor variable (i.e., spiritual well-being) should be related to the dependent variable (i.e., generalized anxiety disorder), (b) the predictor should be associated with the mediator 
TABLE 2. Stepwise-regression analysis of dimensions of spiritual wellbeing as predictors and intensity of symptoms of Generalized Anxiety Disorder as an outcome variable

\begin{tabular}{|c|c|c|c|c|c|c|c|}
\hline \multirow[b]{2}{*}{ Predictors } & \multicolumn{7}{|c|}{$\begin{array}{l}\text { Outcome } \\
\text { GAD }\end{array}$} \\
\hline & $R$ & $R^{2}$ & $\Delta R^{2}$ & $R^{2}$ change & $B$ & $\beta$ & $t$ \\
\hline $\begin{array}{l}\text { Step } 1 \\
\text { Concept of } \\
\text { Hereafter }\end{array}$ & .53 & .28 & .26 & .28 & -.92 & $-.53^{\star \star}$ & -3.85 \\
\hline $\begin{array}{l}\text { Step } 2 \\
\text { Concept of } \\
\text { Hereafter }\end{array}$ & .53 & .28 & .26 & .28 & -.83 & $-.48^{\star \star}$ & -4.06 \\
\hline Mystery & .69 & .49 & .46 & .21 & -.74 & $-.46^{\star \star}$ & -3.88 \\
\hline $\begin{array}{l}\text { Step } 3 \\
\text { Concept of } \\
\text { Hereafter }\end{array}$ & .53 & .28 & .26 & .28 & -.66 & $-.38^{\star \star}$ & -3.14 \\
\hline $\begin{array}{l}\text { Mystery } \\
\text { Meaning }\end{array}$ & .69 & .49 & .46 & .21 & -.65 & $\begin{array}{l}-.40^{\star \star} \\
-26^{*}\end{array}$ & -3.50 \\
\hline
\end{tabular}

Note: $\Delta R^{2}=$ Adjusted $R^{2}$ (explained variance), $B=$ Unstandardized Coefficient, $\beta=$ Standardized Coefficient, GAD $=$ Generalized Anxiety Disorder.

${ }^{\star} p<0.05 .{ }^{* *} p<0.01$.

(i.e., coping strategies), (c) the mediator should be related with the dependent variable, and (d) the significant relationship between predictor and outcome variable is significantly reduced or no longer remains significant when the mediator is controlled statistically.

Two independent mediation analyses were conducted, one for active practical coping strategies, and the other for religious coping strategies; two of the four types of coping strategies had significant positive correlation with spiritual wellbeing and significant negative correlation with GAD symptoms. However, the correlations of the other two types of coping strategies (i.e., activedistracting and avoidance-focused coping strategies) were nonsignificant. For mediation analysis, spiritual wellbeing was considered as a predictor, active practical and religious coping strategies were taken as mediators, and symptoms of GAD as an outcome variable. For this purpose, three independent regression analyses were conducted. In the first linear regression analysis, spiritual wellbeing was taken as a predictor and GAD as an outcome. This analysis showed that spiritual wellbeing significantly predicted GAD symptoms in a negative direction $\left(R^{2}=.41, \beta=-.64, p=.000\right)$. In the second linear regression analysis, spiritual wellbeing (predictor) and active-practical coping strategies (mediator as outcome) were evaluated. The result of this analysis demonstrated that spiritual wellbeing significantly and positively predicted active-practical coping strategies $\left(R^{2}=.21, \beta=.47, p=.002\right)$. According to Baron and Kenny's (1986) statistical model of mediation, if mediation of coping strategy has to 
TABLE 3. Series of regression analysis showing active-practical coping strategies as mediator between spiritual wellbeing and symptoms of Generalized Anxiety Disorder $(n=40)$

\begin{tabular}{|c|c|c|c|c|c|c|c|c|}
\hline Predictors & Constant & $R$ & $R^{2}$ & $\Delta R^{2}$ & $B$ & $\beta$ & $t$ & $p$ \\
\hline \multicolumn{9}{|c|}{ Linear Regression Analysis with GAD as Outcome } \\
\hline Spiritual wellbeing & 46.84 & .64 & .41 & .39 & -.18 & $-.64^{\star \star \star}$ & -5.16 & .00 \\
\hline \multicolumn{9}{|c|}{ Linear Regression Analysis with Active Practical Coping as Outcome } \\
\hline Spiritual wellbeing & -.14 & .46 & .21 & .20 & .04 & $.47^{\star \star}$ & 3.25 & .00 \\
\hline \multicolumn{9}{|c|}{$\begin{array}{l}\text { Hierarchical Stepwise-Regression Analysis with GAD as Outcome } \\
\text { Step } 1\end{array}$} \\
\hline $\begin{array}{l}\text { Active Practical } \\
\text { Coping }\end{array}$ & 22.68 & .32 & .10 & .08 & -1.06 & $-.32^{*}$ & -2.10 & .04 \\
\hline Step 2 & & & & & & & & \\
\hline $\begin{array}{l}\text { Active Practical } \\
\text { Coping }\end{array}$ & 22.68 & .32 & .10 & .08 & -.09 & -.03 & -0.21 & .84 \\
\hline Spiritual wellbeing & 46.83 & .64 & .41 & .38 & -.17 & $-.63^{\star \star \star}$ & -4.41 & .00 \\
\hline
\end{tabular}

Note: $\Delta R^{2}=$ Adjusted $R^{2}$ (explained variance), $B=$ Unstandardized Coefficient, $\beta=$ Standardized Coefficient, GAD $=$ Generalized Anxiety Disorder.

${ }^{*} p<0.05 .{ }^{* *} p<0.01,{ }^{* \star *} p<.001$.

TABLE 4. Series of regression analysis showing religious-focused coping strategies as mediator between spiritual wellbeing and symptoms of Generalized Anxiety Disorder $(n=40)$

\begin{tabular}{|c|c|c|c|c|c|c|c|c|}
\hline Predictors & Constant & $R$ & $R^{2}$ & $\Delta R^{2}$ & $B$ & $\beta$ & $t$ & $p$ \\
\hline \multicolumn{9}{|c|}{ Linear Regression Analysis with GAD as Outcome } \\
\hline Spiritual wellbeing & 46.84 & .64 & .41 & .39 & -.18 & $-.64^{\star \star \star}$ & -5.16 & .00 \\
\hline \multicolumn{9}{|c|}{ Linear Regression Analysis with Religious Focused Coping as Outcome } \\
\hline Spiritual wellbeing & 1.11 & .40 & .16 & .14 & .03 & $.40^{\star \star}$ & 2.72 & .01 \\
\hline \multicolumn{9}{|c|}{$\begin{array}{l}\text { Hierarchical Stepwise Regression Analysis with GAD as Outcome } \\
\text { Step } 1\end{array}$} \\
\hline $\begin{array}{l}\text { Religious Focused } \\
\text { Coping }\end{array}$ & 21.83 & .26 & .07 & .04 & -.93 & -.26 & -1.72 & .09 \\
\hline \multicolumn{9}{|l|}{ Step 2} \\
\hline $\begin{array}{l}\text { Religious Focused } \\
\text { Coping }\end{array}$ & - & - & - & - & - & - & - & - \\
\hline Spiritual wellbeing & - & - & - & - & - & - & - & - \\
\hline
\end{tabular}

Note: $\Delta R^{2}=$ Adjusted $R^{2}$ (explained variance), $B=$ Unstandardized Coefficient, $\beta=$ Standardized co-efficient, GAD = Scores of Generalized Anxiety Disorder, - = Step 2 is not applicable due to nonsignificant step 1 .

${ }^{\star} p<0.05 .{ }^{* *} p<0.01,{ }^{* \star *} p<.001$. 
occur between the relationship of spiritual wellness and GAD, then the predictor (spiritual wellbeing) would not have a significant effect on outcome (GAD) when the mediator (active-practical coping strategies) is controlled. In order to determine this, a third hierarchical stepwise-regression analyses was run. In model 1, GAD was taken as a dependent (outcome variable) and active coping strategies (mediator) were entered as an independent variable; in model 2, GAD remained as a dependent variable and spiritual wellbeing (predictor) was taken as an independent variable. The result of model 1 showed that activepractical coping strategies significantly predicted GAD symptoms in a negative direction $\left(R^{2}=.10, \beta=-.32, p=.042\right)$. The results of model 2 revealed that the spiritual wellbeing remained a strong predictor of $\operatorname{GAD}\left(R^{2}=.41, \beta=-.63, p=\right.$ $.000)$, even after controlling the active-practical coping strategies. Thus, it was demonstrated that active-practical coping strategies did not mediate between spiritual wellbeing and GAD symptoms, but, rather, spiritual wellbeing had a direct effect on GAD. This analysis was later confirmed by Sobel z-test of mediation (1982), showing nonsignificant mediation effect of active practical coping strategies $(p=.075)$.

Similar mediation analysis and Sobel z-test were run for religious-focused coping strategies. It found that religious coping did not mediate between the relationship of spiritual wellbeing and coping strategies. The results of linear regression analyses showed that spiritual wellbeing significantly and positively predicted religious-focused coping strategies $\left(R^{2}=.16, \beta=.41, p=.010\right)$. The next regression analyses showed that religious-focused coping strategies did not significantly predict symptoms of $\mathrm{GAD}\left(R^{2}=.07, \beta=-.27, p=.094\right)$. Therefore, further steps for mediation for religious coping strategies could not be performed. The analyses were later confirmed by Sobel z-test of mediation, showing nonsignificant mediation effect of religious-focused coping strategies $(p=.144)$.

The mediation analysis for the 13 dimensions of spiritual wellness could not be performed, as the four conditions of mediation analysis proposed by Baron and Kenny were not fulfilled. According to the first condition, of the 13 dimensions of spiritual wellness as predictors, only three dimensions (i.e., concept of hereafter $(\beta=-0.53, p=.00)$, meaning $(\beta=-0.26, p=.04)$, and mystery $(\beta=-0.46, p=.00))$ significantly negatively predicted GAD as a dependent variable. The $R^{2}=.62$ of the first linear regression analysis showed that all 13 dimensions of spiritual wellbeing predicted $62 \%$ variation in GAD symptoms. In order to fulfill the second condition of mediation analysis, no dimension was significantly predicted with active-practical coping strategies or religious coping strategies. However, three dimensions (i.e., concept of hereafter $(\beta=$ $-0.72, p=.00)$, mystery $(\beta=-0.38, p=.05)$, and knowledge $(\beta=0.42, p=.02))$ were significantly related to active-distracting coping strategies. This analysis gave $R^{2}=.50$, depicting $50 \%$ of variation in active-distracting coping strategies 
Figure 1. Summarizing the results of the mediation analysis (based on Baron and Kenny statistical model of mediation, 1986). In this figure of mediation the lines with single sided arrow head represent correlations, while the lines with both sided arrow head show regression. The dash qualities of lines depict non-significant correlations and regression. $\beta$ and $B$ shows the standardized and unstandardized regression coefficients respectively of predictor before controlling the mediator and $\beta^{\prime}$ and $\mathrm{B}^{\prime}$ shows the standardized and unstandardized regression coefficients respectively of predictor after controlling the mediator.

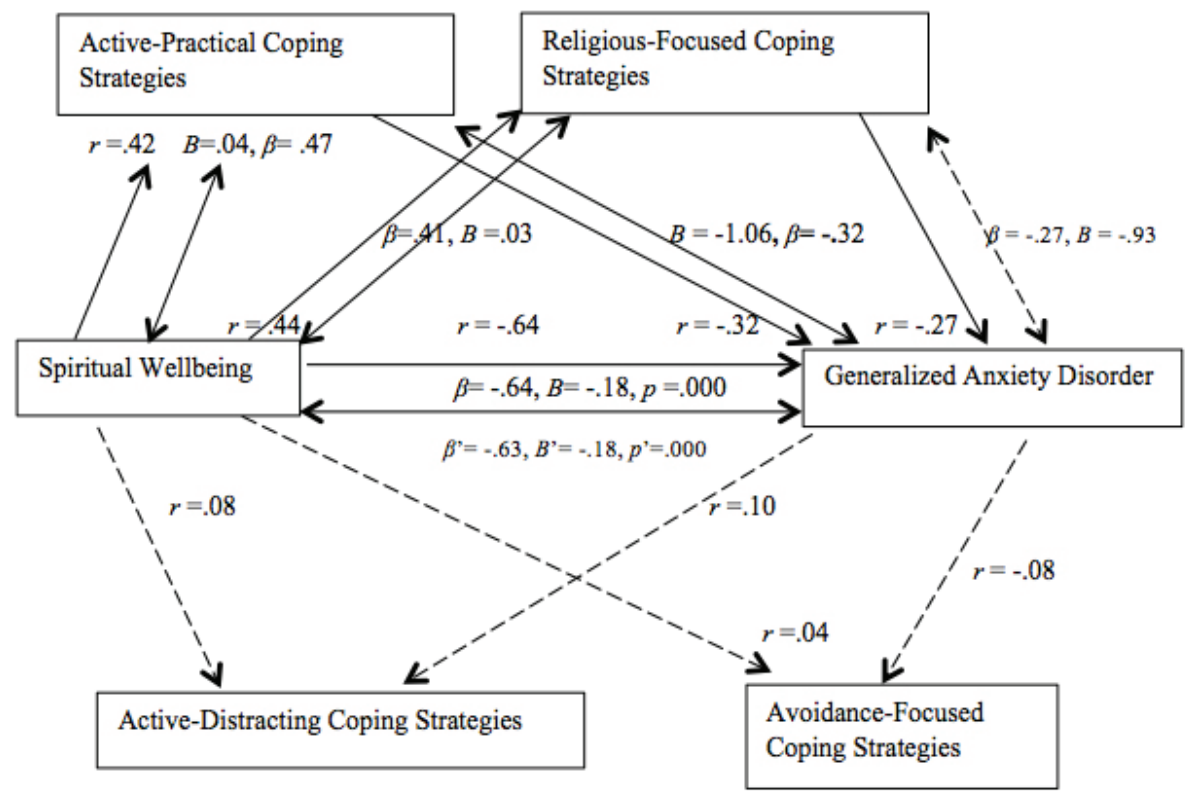

was due to 13 dimensions of spiritual wellbeing. Similarly, the dimension of forgiveness $(\beta=0.42, p=.05)$ was related with avoidance-focused coping strategies, and $R^{2}=.36$ showed $36 \%$ variation in avoidance-focused coping strategies was due to all the dimensions of spiritual wellbeing. For fulfillment of the third mediation condition, the active-distracting coping strategies $\left(R^{2}=.01, \beta\right.$ $=0.10, p=.52)$ and avoidance-focused coping strategies $\left(R^{2}=.006, \beta=-0.08\right.$, $p=.62$ ) failed to show significant relation with GAD as a dependent variable. The mediation analysis with the dimensions of concept of hereafter and mystery could be done if active-distracting coping strategies significantly predicted $\mathrm{GAD}$, as these two dimensions were also significantly related with GAD. 


\section{Discussion}

The main purpose of the present research was to investigate the impact of spiritual wellbeing and coping strategies on patients with Generalized Anxiety Disorder. It was hypothesized that the different dimensions of spiritual wellbeing would negatively predict the intensity of symptoms of GAD. The results showed that, of 13 dimensions, only three (i.e., concept of the hereafter, mystery, and meaning) significantly and negatively predicted the intensity of GAD symptoms. Ingersoll (1998) proposed that the spiritual dimension of meaning is expressed in the form of a sense of having a life worth living, a purposeful life, and of being at peace. Meaninglessness in life may result into various psychopathologies (Frankl, 1964; Maslow, 1964) and spirituality restores the purpose and meaning of the life, which, in turn, reduces mental distress (Cornah \& Ryrie, 2006). The present research finding that meaning in life predicts less GAD is consistent with Graybill and Esquivel's (2012) findings, which reported that meaning and purpose in life predicted lower depression rates among the mothers of children with Autism Spectrum Disorders. The results of a meta-analysis study conducted by Westgate (2011) also reported that a sense of meaning in life predicted less depression. Maslow (1964) regarded neurosis as a "spiritual disorder", because the absence of a spiritual life can lead a person toward meaninglessness, hopelessness, and the impossibility of feeling joy or love. Maslow's view was later supported by Koenig and colleagues (2001). If individuals have a meaningful life, they would be less vulnerable to develop anxieties and other psychopathologies.

Ingersoll suggested that the spiritual dimension of mystery measures a person's comfort level and ways of dealing with the ambiguities and uncertainties of life. Worry is the hallmark symptom of GAD, and is future-oriented, as described by Wells (1999). The future is always unpredictable, so it can be inferred that more sense of purpose in life and being more comfortable dealing with life's uncertainties can lead to less worry, which, in turn, may decrease the intensity of GAD. The finding that mystery predicts fewer GAD symptoms is in accordance with Al-Qarni's (2003) notion that preoccupation with past and future can lead to an unhealthy and unstable mind. Bonab, Miner, and Proctor (2013) proposed that the core element of Islamic spirituality is attachment to God. This attachment provides protection and safety, and comforts the person during difficult situations in life. Thus, high score in the mystery dimension can reflect an individual's courage and comfort level to deal with ambiguities, uncertainties, and threats of life.

The results also demonstrate that the third dimension of spiritual wellbeing (i.e., concept of hereafter) also predicted fewer GAD symptoms. It can be supported by religious literature, for example, in a hadith, the Prophet Muhammad was reported saying: 
"Whoever has the hereafter as his main concern, God will fill his heart with a feeling of richness and independence; he will be focused and content, and this world will come to him in spite of it. Whoever has this world as his main concern, God will cause him to feel constant fear of poverty; he will be distracted and unfocused, and he will have nothing of this world except what was already predestined for him" (Al-Munajjid, 1999, p. 26).

Furthermore, Al-Ghazali (1910) explained that life after death can be considered as a blessing, as it allows a person to view his life's sufferings as shortterm. Moreover, belief that perseverance in the face of these difficulties will be rewarded after death. This concept of hereafter serves as a means of cognitive restructuring in the face of concerns and worries and has a therapeutic effect on one's mental health, as concentrating on the temporary nature of life makes it easy to cope with stressors. Rather, to suffer from excessive worries and concerns of this life, a person, believing in a hereafter, directs efforts to concentrate on an everlasting life (Hamdan, 2008). Hence, high scores in the spiritual dimension of concept of hereafter predicts less intensity of GAD as the spiritual person does excessively worry about minor issues in daily life.

Secondly, it was proposed that the coping strategies would mediate the relationship between spiritual wellbeing and Generalized Anxiety Disorder. The results of the present study did not prove this hypothesis. It revealed that spiritual wellbeing has a direct and negative effect on the severity of symptoms of GAD. The spiritual wellbeing did not have an effect on severity of GAD indirectly (i.e., through the path of coping strategies). This finding is in accordance with Al-Ghazali's proposition (cited in Abdullah, Ismail, Ahmad, \& Hissan, 2012) that full trust and complete reliance on God empowers a person to get relief from anxieties and fears in life. Furthermore, different studies proved the effectiveness of spiritual-based therapy given to the participants with GAD (Abdullah et al., 2012; Barrera et al. 2012; Koszycki, Raab, Aldosary, \& Bradwejn, 2010; Rosmerin et al. 2010). Similarly, Watlington and Murphy's (2006) research also demonstrated that religious coping did not mediate the relationship between spirituality, and depressive and posttraumatic stress symptoms. Though the hypothesized model of mediation remained insignificant, it revealed that, in Pakistani Muslim culture, the concept of the divine and feeling of connectedness with God is so strong that it has a direct influence on people's mental health. In other words, strong spiritual roots directly predict better mental health and also help in decreasing the intensity of excessive worry and apprehension.

Cornah and Ryrie (2006) reviewed the research conducted on Jewish and Christian populations in order to explore the mechanisms through which spirituality affect mental health. They found coping styles, locus of control, social support, and physical health as mediating factors. Cornah and Ryrie suggested 
that spirituality is associated with the acquisition of adaptive coping strategies, gives an internal locus of control, strengthens social networks by providing a sense of belonging, and related to health-promoting behaviors like meditation and exercise. The present research demonstrated that, in a Pakistani Muslim population, spiritual wellbeing did not reduce the intensity of Generalized Anxiety Disorder via coping strategies; rather, it had a direct impact on GAD, as well as independently predicting active-practical and religious coping strategies. More research with different mental disorders and in different populations are needed in order to explore mediating factors of spiritual wellbeing and the mental health of Muslims.

\section{Limitations and Suggestions}

The limitations are a) the sample size was rather small and the data were collected from government teaching hospitals that are not representative of upper socioeconomic class, so in the sample, this class was least represented. The authors suggest using a larger sample size, one that would be representative of all socioeconomic classes; b) Though the tool used to measure spiritual wellbeing in the present study was not religiously biased, it was not indigenous. It is suggested that future studies should explore this phenomenon by using indigenous tools; c) It is important to carry out an in-depth study on spirituality through qualitative research methodology, rather than relying on numeric values of spiritual wellbeing, as spirituality is a subjective experience in which individual differences are quite marked.

\section{Implication of findings}

One of the implications of the results is the importance of a holistic (i.e. biopsycho-socio and spiritual) conceptualization of patients with mental disorders, and points toward the need to use spirituality-integrated therapy in intervention.

\section{References}

Abdullah, C. H., Ismail, H. N., Ahmad, N. S. H., \& Hissan, W. S. M. (2012). Generalized Anxiety Disorder (GAD) from Islamic and western perspectives. World Journal of Islamic History and Civilization, 2, 44-52.

Al-Ghazali, A. H. (1910). The alchemy of happiness (C. Field, Trans.). Retrieved from https://docs.google.com/viewer?url=http\%3A\%2F\%2Fmajalla. org\%2Fbooks\%2F2005\%2FThe-Alchemy-of-Happiness.pdf

Al-Munajjid, M. S. (1999). Islam's treatment for anxiety and stress. Riyadh, Saudi Arabia: International Islamic Publishing House. 
Al-Qarni, A. A. (2003). Don't be sad (M. F. Shafeeq, Trans.). Riyadh, Saudi Arabia: International Islamic Publishing House.

American Psychiatric Association. (2000). Diagnostic and statistical manual of mental disorders (4th ed., text rev). Washington, DC: APA.

Barbarin, O. (1993). Coping and resilience: Exploring the inner lives of African American children. Journal of Black Psychology, 19, 472-498. http://dx.doi. org/10.1177/00957984930194007

Baron, R. M., \& Kenny, D. A. (1986). The moderator-mediator variable distinction in social psychological research: Conceptual, strategic, and statistical considerations. Journal of Personality and Social Psychology, 51, 1173-1182. http://dx.doi. org/10.1037/0022-3514.51.6.1173

Barrera, T. L., Zeno, D., Bush, A. L., Barber, C. R., \& Stanley, M. A. (2012). Integrating religion and spirituality into treatment for late-life anxiety: Three case studies. Cognitive and Behavioral Practice, 19, 346-358. http://dx.doi.org/10.1016/j. cbpra.2011.05.007

Batool, N. (2009). Spiritual wellness and quality of life as predictors of delinquent tendencies among adolescents (Unpublished master's thesis). National Institute of Psychology, Quaid-e-Azam University, Islamabad, Pakistan.

Bensley, R. J. (1991). Defining spiritual health: A review of the literature. Journal of Health Education, 22, 287-290.

Bonab, B. G., Miner, M., \& Proctor, M. (2013). Attachment to God in Islamic spirituality. Journal of Muslim Mental Health, 7. 77-104.

Campbell, J. (1969). The flight of the wild gander: Explorations in the mythological dimensions. New York: Viking.

Carver, C. S., Scheier, M. F., \& Weintraub, J. K. (1989). Assessing coping strategies: A theoretically based approach. Journal of Personality and Social Psychology, 56, 267-283. http://dx.doi.org/10.1037/0022-3514.56.2.267

Cornah, D., \& Ryrie, L. (2006). The impact of spirituality on mental health: A review of the literature. London: Mental Health Foundation

Delpisheh, S. R. M. A. (2012). Concept of spiritual health in Descartes' and Tabatabaei's perspectives. Journal for the Study of Religions and Ideologies, 11(32), 93-108.

Elkins, D. N. (1999). Spirituality. Psychology Today, 32, 44-47.

Elkins, D. N., Hedstrom, L. J., Hughes, L. L., Leaf, J. A., \& Saunders, C. (1988). Towards a humanistic-phenomenological spirituality. Journal of Humanistic Psychology, 28(4), 5-18. http://dx.doi.org/10.1177/0022167888284002

Ellison, C. W. (1982). Spiritual well-being: Conceptualization and measurement. Journal of Psychology and Theology, 11, 330-340.

Faul, F., Erdfelder, E., Buchner, A., \& Lang, A. G. (2009). Statistical power analyses using $\mathrm{G}^{\star}$ Power 3.1: Tests for correlation and regression analyses. Behavior Research Methods, 41, 1149-1160. http://dx.doi.org/10.3758/BRM.41.4.1149

Fisher, J. (2011). The four domains model: Connecting spirituality, health and wellbeing. Religions, 2, 17-28. http://dx.doi.org/10.3390/rel2010017

Frankl, V. E. (1964). Man's search for meaning: An introduction to logotherapy. London: Hodder and Stoughton.

Gelder, M., Gath, D., Mayou, R., \& Cowen, P. (1987). Oxford book of psychiatry. New York: Oxford University Press.

Gohar, M. (2005). Development of an indigenous spiritual wellness inventory for Pakistani youth (Unpublished master's thesis). National Institute of Psychology, Islamabad, Pakistan. 
Gomez, R., \& Fisher, J. W. (2003). Domains of spiritual well-being and development and validation of the spiritual well-being questionnaire. Personality and Individual Differences, 35, 1975-1991. http://dx.doi.org/10.1016/S01918869(03)00045-X

Graybill, A., \& Esquivel, G. (2012). Spiritual wellness as a protective factor in predicting depression among mothers of children with autism spectrum disorders. Journal of Religion, Disability and Health, 16(1), 74-87. http://dx.doi.org/10.1080/152 28967.2012.645591

Hamdan, A. (2008). Cognitive restructuring: An Islamic perspective. Journal of Muslim Mental Health, 3, 99-116. http://dx.doi.org/10.1080/15564900802035268

Hefti, R. (2011). Integrating religion and spirituality into mental health care, psychiatry and psychotherapy. Religions, 2, 611-627. http://dx.doi.org/10.3390/rel2040611

Hill, P. C., Pargament, K. I., Hood, W, Jr., McCullough, M. E., Swyers, J. P., Larson, D. B., et al. (2000). Conceptualizing religion and spirituality: Points of commonality, points of departure. Journal for the Theory of Social Behavior, 30, 51-77. http:// dx.doi.org/10.1111/1468-5914.00119

Ingersoll, R. E. (1994). Spirituality, religion, and counseling: Dimensions and relationships. Counseling and Values, 38, 98-111. http://dx.doi.org/10.1002/j.2161007X.1994.tb00827.x

Ingersoll, R. E. (1998). Refining dimensions of spiritual wellness: A cross-traditional approach. Counseling and Values, 42, 156-165. http://dx.doi.org/10.1002/j.2161007X.1998.tb00421.x

Ingersoll, R. E., \& Bauer, A. L. (2004). An integral approach to spiritual wellness in school counseling settings. Retrieved from http://johnhawkinslpc.com/PDF/Spirituality/Integral.pdf

Kausar, R., \& Munir, R. (2004). Pakistani adolescents' coping with stress: Effects of loss of a parent and gender of adolescents. Journal of Adolescence, 27, 599-610. http:// dx.doi.org/10.1016/j.adolescence.2003.11.015

Koenig, H. G., George, L. K., \& Titus, P. (2004). Religion, spirituality, and health in medically ill hospitalized older patients. Journal of American Geriatrics Society, 52, 554-562. http://dx.doi.org/10.1111/j.1532-5415.2004.52161.x

Koenig, H. G., McCullough, M. E., \& Larson, D. B. (2001). Handbook of religion and health. New York: Oxford University Press. http://dx.doi.org/10.1093/acprof:o so/9780195118667.001.0001

Koszycki, D., Raab, K., Aldosary, F., \& Bradwejn, J. (2010). A multifaith spiritually based intervention for generalized anxiety disorder: A pilot randomized trial. Journal of Clinical Psychology, 66, 430-41.

Lazarus, R. S., \& Folkman, S. (1984). Stress appraisal and coping. New York: Springer.

Maselko, J., Gilman, S. E., \& Buka, S. (2009). Religious service attendance and spiritual well- being are differentially associated with risk of major depression. Psychology Medicine, 39, 1009-1017. http://dx.doi.org/10.1017/S0033291708004418

Maslow, A. H. (1964). Religions, values, and peak experiences. Columbus, OH: Ohio State University Press.

Moberg, D. O. (2002). Assessing and measuring spirituality: Confronting dilemmas of universal and particular evaluative criteria. Journal of Adult Development, 9, 47-60. http://dx.doi.org/10.1023/A:1013877201375

Mohamed, Y. (1998). Human nature in Islam. Kuala Lumpur: Noordeen.

Pargament, K. I., Olsen, H., Reilly, B., Falgout, K., Ensing, D., \& Van Haitsma, K. (1992). God help me (II): The relationship of religious orientations to religious coping 
with negative life events. Journal for the Scientific Study of Religion, 31, 504-513. http://dx.doi.org/10.2307/1386859

Perez, J. E., Chartier, M., Koopman, C., Vosvick, M., Gore-Felton, C., \& Spiegel, D. (2009). Spiritual striving, acceptance coping, and depressive symptoms among adults living with HIV/AIDS. Journal of Health Psychology, 14(1), 88-97. http:// dx.doi.org/10.1177/1359105308097949

Preacher, K. J., \& Leonardelli, G. J. (n. d). Calculation for the sobel test: An interactive calculation tool for mediation tests. Retrieved from http://quantpsy.org/sobel/sobel.htm

Rosmarin, D. H., Pargament, K. I., Pirutinsky, S., \& Mahoney, A. (2010). A randomized controlled evaluation of a spiritually integrated treatment for subclinical anxiety in the Jewish community, delivered via the Internet. Journal of Anxiety Disorders, 24, 799-808. http://dx.doi.org/10.1016/j.janxdis.2010.05.014

Smith, D. W. (1994). Theory of spirituality. Retrieved from http://housesofhealing.com/ source/Spirarticle94.pdf

Watlington, C. G., \& Murphy, C. M. (2006). The roles of religion and spirituality among African American survivors of domestic violence. Journal of Clinical Psychology, 62, 837-857. http://dx.doi.org/10.1002/jclp.20268

Wells, A. (1999). Cognitive therapy of anxiety disorders: A practice manual and conceptual guide. New York: J. Wiley \& Sons.

Westgate, C. E. (2011). Spiritual wellness and depression. Journal of Counseling and Development, 75(1), 26-35. http://dx.doi.org/10.1002/j.1556-6676.1996.tb02311.x 